DOI: 10.20472/IAC.2018.935.023

JUDIT KAPAS

University of Debrecen, Hungary

\title{
DIFFERENT CULTURAL LAYERS: DIFFERENT EFFECTS ON DEVELOPMENT?
}

\begin{abstract}
:
This paper relies on the idea that culture has several layers which can be separated on the basis of the degree of stickiness between a particular cultural component and formal institutions. This procedure, by allowing us to focus on more specific questions as to how culture affects development, helps improve the somewhat controversial empirical results of the literature.

As an extension of the theory of institutional stickiness (Boettke et al. 2008), I distinguish two cultural layers: a rigid and a slow-moving layer. The rigid layer includes values reflecting the most basic norms, judgments, and beliefs, which do not change. The slow-moving layer includes those cultural components that depend upon individuals' circumstances and the prevailing institutions, and can change if these change. The degree of stickiness between the slow-moving layer and institutions is very high because institutions find their roots directly in that cultural layer. However, the rigid layer and institutions are a bit "farther" from one other, which allows a certain degree of divergence from a perfect correspondence between them.

In the cross-country empirical analyses, including IV estimations, I check the hypotheses derived from this stickiness model, and focus on how a particular cultural layer operating in conjunction with institutions affects development. When it comes to the rigid layer proxied by individual values (Schwartz 1999), besides establishing that both values and institutions are strong determinants of development, I also find that their interaction acts as a separate factor. This means that values are not fully embodied in institutions. The effect of the slow-moving layer proxied by trust (WVS), however, is very different: trust does not exert an impact on development once institutions are controlled for, and there is no interaction between them, meaning that trust is crystallized in institutions. The results are very robust to alternative variables and specifications.
\end{abstract}

\section{Keywords:}

instututions, culture, economic development

JEL Classification: E02, 043 